\title{
Temporary Gastric Stimulation in Patients With Gastroparesis Symptoms: Low-Resolution Mapping Multiple Versus Single Mucosal Lead Electrograms
}

\author{
Mohsen Hasanin ${ }^{\mathrm{a}}$, Om Amin ${ }^{\mathrm{b}}$, Hamza Hassan ${ }^{\mathrm{a}}$, Archana Kedar ${ }^{\mathrm{a}}$, \\ Michael Griswold ${ }^{c}$, Thomas L. Abell ${ }^{\mathrm{a}, \mathrm{d}}$
}

\begin{abstract}
Background: Cajal cells have a fundamental role in generating slow waves that regulate gastric motility. Gastric electrical stimulation (GES) is Food and Drug Administration (FDA)-approved for symptomatic treatment of drug refractory gastroparesis. We hypothesized that using two leads will vary from a single lead by providing greater insight of gastric electrical wave propagation, through differences in measured frequency, amplitude, and frequency over amplitude ratio. We also hypothesized that a significant reduction in symptomatic vomiting score is highly predictive in a single lead temporary gastric electrical stimulation.
\end{abstract}

Methods: A total of 111 patients with drug-refractory gastroparesis were enrolled. Forty-two patients had single lead, while 69 patients had two leads. All recordings measured mean frequency and amplitude in each lead. Patients documented symptoms using standardized symptom scores at baseline and day 5 post-procedure.

Results: Single lead patients with initial low mucosal frequency showed an increase from 3.10 to $4.93(\mathrm{P}=0.0155)$, while the high frequency group decreased from 5.89 to $5.12(\mathrm{P}=0.135)$. Vomiting score decreased significantly among both groups with GES (P = 0.0001). For two leads, the mucosal frequency decreased at the proximal electrode $(\mathrm{P}=0.402)$, and increased at the distal electrode $(\mathrm{P}=$ $0.514)$, neither statistically significant $(P=0.143)$. Mucosal electrogram amplitude values changed for both proximal, mean decrease of $0.34 \mathrm{mV}(\mathrm{P}=0.241)$, and distal, mean increase of $0.05 \mathrm{mV}(\mathrm{P}=0.65)$ with a mean difference $0.34 \mathrm{mV}(\mathrm{P}=0.238)$. However, mucosal electrogram frequency and amplitudes on day 5 were highly dependent on

Manuscript submitted January 15, 2019, accepted March 27, 2019

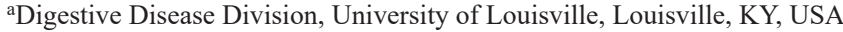
${ }^{b}$ Digestive Disease Division, University of West Virginia, Morgantown, WV, USA

'Division of Biostatistics and Bioinformatics, University of Mississippi, Jackson, MS, USA

${ }^{\mathrm{d} C}$ Corresponding Author: Thomas L. Abell, Division of Gastroenterology, Hepatology and Nutrition, University of Louisville, 550 S. Jackson Street, ACB A3L15, Louisville, KY 40202, USA.

Email: thomas.abell@louisville.edu

doi: https://doi.org/10.14740/gr1127 the baseline values $(\mathrm{P}<0.001)$.

Conclusions: Compared to the use of single point electrodes, the use of two low-resolution electrodes allows recording gastric electrical wave propagation with greater detail. Low resolution recording appears to be superior to single point recordings, while awaiting practical high-resolution recordings.

Keywords: Gastroparesis; Nausea; Vomiting; Electrical stimulation

\section{Introduction}

Gastroparesis is a complex gastrointestinal motility disorder that most often affects young and middle-aged women [1]. Patients often present with nausea, abdominal pain, early satiety, vomiting, and bloating [2]. Many patients with gastroparesis undergo gastric electrical stimulation (GES) when drugs do not prove beneficial. GES has been found effective in alleviating symptoms of gastroparesis, but its physiologic effects are not well understood. We examined the electrophysiologic responses of gastric mucosa as measured by mucosal electrogram $(\mathrm{mEG})$ at baseline and after electrical stimulation with one implantable lead temporary GES (tGES). Furthermore, we measured changes in gastric emptying tests (GET) before and after tGES.

The use of multiple electrodes for endoscopic tGES allows for the ability to record the effect of GES on electrical rhythm in addition to low-resolution gastric mapping. The physiologic slow wave frequency of gastric motility is three cycles per minute (cpm) [3-6]. In a previous study measuring serosal electrograms in gastroparesis patients with permanent GES (pGES) implantation, the mean frequency improved from $5.06 \mathrm{cpm}$ pre-stimulation to $3.66 \mathrm{cpm}$ post-stimulation [7]. We hypothesized that changes in mucosal electrogram patterns would occur with tGES irrespective if measured with a single lead or with two leads, and that using two leads will provide greater insight of gastric electrical wave propagation, through differences in measured frequency, amplitude, and frequency over amplitude ratio. We hypothesized that change in gastrointestinal symptoms, especially the vomiting score (VS) as well as in gastric emptying may be observed via one im- 
plantable lead tGES. We further hypothesized that there would be a change observed in mean frequency, amplitude, and the frequency-amplitude ratio (FAR) with tGES via one lead versus two implantable leads. It has been speculated that electrical gastric waves depending on location and recent studies using multiscale models and high-resolution mapping confirm that slow waves vary at different parts of the stomach $[8,9]$. A number of other studies using simultaneous serosal and cutaneous recordings [9-13], as well as mucosal recordings [6, 14, 15] have confirmed that the electrogram frequency correlates with the gastric slow wave frequency; these changes may be further captured by mucosal electrogram using multiple electrodes.

Gastric electrical stimulation (Enterra, Medtronics, Inc.) was approved by Food and Drug Administration (FDA) in 2000 as a Humanitarian Use Device for patients with refractory diabetic or idiopathic gastroparesis [16] and as a surgically implanted pGES device. The implanted permanent pulse generator delivers high frequency $(12 \mathrm{cpm})$ of pulse trains, low energy $(5 \mathrm{~mA})$ stimulation at pulse width of $330 \mu \mathrm{s}$, with pulse trains of $14 \mathrm{~Hz}$ when the device is on (for $0.1 \mathrm{~s}$ ) but not when off $(5 \mathrm{~s})$. High frequency/low energy GES has been noted in prior studies to reduce nausea and vomiting with slightly improved liquid gastric emptying in gastroparesis patients [1719]. Given that gastroparesis patients who respond to pGES often do so relatively soon after implantation of the device [20], this has led to the proposal that tGES via endoscopic placement of leads in the stomach can be used to predict response to the permanent device. A study on tGES via orally or PEG-placed electrodes has shown improved symptom scores in a fashion similar to pGES [21]. TGES uses the same stimulator as pGES, with similar programming parameters: frequency of $14 \mathrm{~Hz}$, amplitude of 5 to $10 \mathrm{~mA}$, and pulse width of 330 $\mu \mathrm{s}[22,23]$ used with $1 \mathrm{~s}$ on and $4 \mathrm{~s}$ off.

GES is an established treatment for drug-refractory gastroparesis. Recent advancements in micro implantable neurostimulators now allow for less-invasive tGES utilizing wireless devices rather than cardiac lead implantation [23]. We hypothesized that there would be different changes observed in mean frequency, amplitude, and the FAR with tGES via one single point lead versus two implantable leads, which would provide for low-resolution gastric electrical mapping.

\section{Materials and Methods}

All patients first received a single electrode placement and later received the second electrode. Patients who provided significant data with the second electrode were added to the 2-electrode group. Patients with an ineffective 2-lead placement or intolerable to the second electrode placement remained in the 1-lead group. By comparing the two groups, it would allow us to compare the possible differences between single lead and double lead/low-resolution mapping mucosal electrogram recordings. Patients were informed of potential side effects such as perforation, bleeding, and lead migration; and in results that the only complication was in lead dislodgement in some patients. Patients all had two visits: the first visit at baseline and
Table 1. Single Lead Demographics

\begin{tabular}{ll}
\hline $\begin{array}{l}\text { Age (years), mean } \pm \text { SD } \\
\text { Gender }\end{array}$ & $45 \pm 15$ \\
$\quad$ Male & $8(19 \%)$ \\
Female & $34(81 \%)$ \\
African Americans & $8(19 \%)$ \\
Etiology of gastroparesis & \\
$\quad$ Idiopathic & $24(57.1 \%)$ \\
Diabetes mellitus & $18(42.9 \%)$ \\
Post-Surgical & $0(0 \%)$ \\
\hline
\end{tabular}

follow-up after placement of lead(s) and receiving tGES on day $5 / 6$.

For the single lead group, electrograms are used to determine frequency, amplitude, and FAR of the gastric mucosa at baseline and after tGES stimulation. Baseline data were used to separate patients into either a high frequency $(>$ or $=3.3$ cycles per minute) or low frequency $(<3.3$ cycles per minute) group. Baseline and post tGES values for frequency, amplitude and FAR were compared for patients in the 1-lead group. Values from the 1-lead group were also compared to gastrointestinal symptom scores reported at baseline and post tGES by patients through a Likert scale, patient-reported outcomes tool $[22,24]$.

For the double lead group, all patients underwent placement of two leads, one in the proximal corpus (PROX) and one in the distal body-antral junction (DIST) prior to tGES. After recovery and before tGES was begun, each electrode was recorded for $10 \mathrm{~min}$ and analyzed by signal averaging techniques for mean frequency and amplitude. At the end of 5 days of stimulation in the DIST lead, we repeated these recordings in 39 patients where both leads remained viable. Results from the 2-lead group were compared using generalized estimating equations (GEE), to account for correlations arising from the repeated measures design. We also examined the contribution of the baseline signal to the signal at day 5 (or 6), reported in a similar manner.

\section{Results}

The single lead group consisted of 42 symptomatic gastroparesis patients ( 34 women, eight men; mean age: $45 \pm 15$ years) and were subdivided based on etiologies: 24 idiopathic and 18 diabetic mellitus patients (Table 1). This group received tGES, a single temporary lead implanted in the gastric mucosa at DIST to deliver electrical stimulation for the treatment of drug refractory gastroparesis.

The double lead group consisted of 69 symptomatic gastroparesis patients (53 females, 16 men; mean age: $50 \pm 15$ years.) and were subdivided based on etiologies: 42 idiopathic, 26 diabetes mellitus and one post-surgical patients (Table 2). This group received tGES, with two temporary leads implanted, one in the proximal stomach and the second in the distal gastric mucosa at the body-antral junction, with the distal lead 
Table 2. Double Leads Demographics

\begin{tabular}{ll}
\hline $\begin{array}{l}\text { Age (years), mean } \pm \text { SD } \\
\text { Gender }\end{array}$ & $47 \pm 14.9$ \\
$\quad$ Male & $16(23.2 \%)$ \\
$\quad$ Female & $53(76.8 \%)$ \\
African Americans & $22(31 \%)$ \\
Etiology of gastroparesis & \\
$\quad$ Idiopathic & $42(60.8 \%)$ \\
Diabetes mellitus & $26(37.6 \%)$ \\
Post-surgical & $1(1.44 \%)$ \\
\hline
\end{tabular}

used to deliver electrical stimulation for the treatment of drug refractory gastroparesis symptoms.

\section{1-lead patient pool}

The 42 patients with one lead were separated into two groups based on initial gastric mucosal frequency (with a cut point of $3.3 \mathrm{cpm}$ ); seven patients in the low frequency group and 35 in the high frequency. The baseline mucosal frequencies of both the low frequency and high frequency groups for all patients moved toward a central point of $5.027 \mathrm{cpm}$ after tGES ( $\mathrm{P}=0.0155$ and 0.1347 , respectively). The FAR for each patient group changed after tGES with low frequency subgroup, which was significant and high frequency subgroup, which was not significant (Table 3). Symptom scores were reduced globally among the two patient subgroups with statistical significance $(\mathrm{P}=0.0001)$, when comparing pre-tGES and post-
tGES (Table 4).

\section{2-lead patient pool}

Using two leads the gastrointestinal signs and symptoms post tGES improved as well in most measures, as noted in Table 5. After 5 days of stimulation, mucosal electrogram (mEG) frequency values decreased for PROX (-0.62 cpm (95\% CI: $-2.07,0.83), \mathrm{P}=0.402)$, while they increased for DIST $(0.44$ cpm (95\% CI: $-0.88,1.76), \mathrm{P}=0.514)$, although the differences were not statistically significant (mean difference 1.28 cpm (95\% CI: $-0.43,3.00), \mathrm{P}=0.143)$. Mucosal EG amplitude decreased for PROX, $(0.34 \mathrm{mV},(95 \% \mathrm{CI}:-0.91,0.23)$, $\mathrm{P}=0.241)$ and increased for DIST, $(0.05 \mathrm{mV}(95 \% \mathrm{CI}:-0.17$, $0.27), \mathrm{P}=0.65)$, although the differences were also not statistically significant with a mean difference of $0.34 \mathrm{mV}((95 \% \mathrm{CI}$ : $-0.23,0.92), \mathrm{P}=0.238)$. However, mucosal $\mathrm{EG}$ frequency and amplitudes on day 5 were highly dependent on the baseline values $(\mathrm{P}<0.001)$ (Fig. 1).

\section{Discussion}

Gastric mechanical contractions are orchestrated electrically through an extensive network of interstitial cells of Cajal (ICC) that generate bioelectrical slow waves transmitted to the electrically-coupled smooth muscle cells at intervals of $20 \mathrm{~s}$ (i.e., $3 \mathrm{cpm}$ ), and at a constant speed, in normal humans, of approximately $3 \mathrm{~mm} / \mathrm{s}$ [12]. Among other abnormalities; reduced ICC mass was directly linked to gastroparesis and delayed gastric emptying as the most prominent factor $[13,25]$. It has also been shown that the severity of ICC loss correlates with

Table 3. The Changes in Frequency After Gastric Electrical Stimulation via 1-lead tGES

\begin{tabular}{lllllll} 
Gastroparesis patients & Initial frequency & Post-GES frequency & P value & Initial ratio & Post-GES ratio & P value \\
\hline All Patients & 5.42012 & 5.09214 & 0.4776 & 18.7357 & 27.0731 & 0.1987 \\
Low frequency (7) & 3.0957 & 4.9314 & $0.0155^{*}$ & 11.3829 & 23.6829 & 0.2602 \\
High frequency (35) & 5.885 & 5.12429 & 0.1347 & 20.2063 & 27.7511 & 0.3153 \\
\hline
\end{tabular}

Frequency reported as $\mathrm{cpm}$ and amplitude reported as $\mathrm{mV}$. *The significant $\mathrm{P}$ values.

Table 4. Changes, in Mean Symptom Score, as Well as Total Gastric Emptying Measured at Baseline and Post-Stimulation via Single Lead tGES

\begin{tabular}{llll}
\hline Variable & Visit $\mathbf{1}$ & Visit $\mathbf{2}$ & Change $(\mathbf{C I})(\mathbf{P}$ value $)$ \\
\hline Nausea & 3.28 & 1.54 & $-1.7(1.25,2.24)(<0.001)^{*}$ \\
Vomiting & 1.96 & 0.51 & $-1.44(0.96,1.93)(<0.001)^{*}$ \\
Anorexia & 2.55 & 1.23 & $-1.32(1.9,0.01)(0.002)^{*}$ \\
Bloating & 2.53 & 1.32 & $-0.26(1.72,1.86)(<0.001)^{*}$ \\
Abdominal pain & 2.35 & 1.32 & $-1.03(0.36,1.71)(0.004)^{*}$ \\
TSS & 12.46 & 5.6 & $-6.86(5.02,8.71)(<0.001)^{*}$ \\
GET total & 153.63 & 141.92 & $-11.71(-9.32,32.73)(0.27)$ \\
\hline
\end{tabular}

TSS: total symptom score; GET total: total gastric emptying time. All "Visit 2" values were recorded 5 days after baseline at visit 1. *The significant $P$ values. 


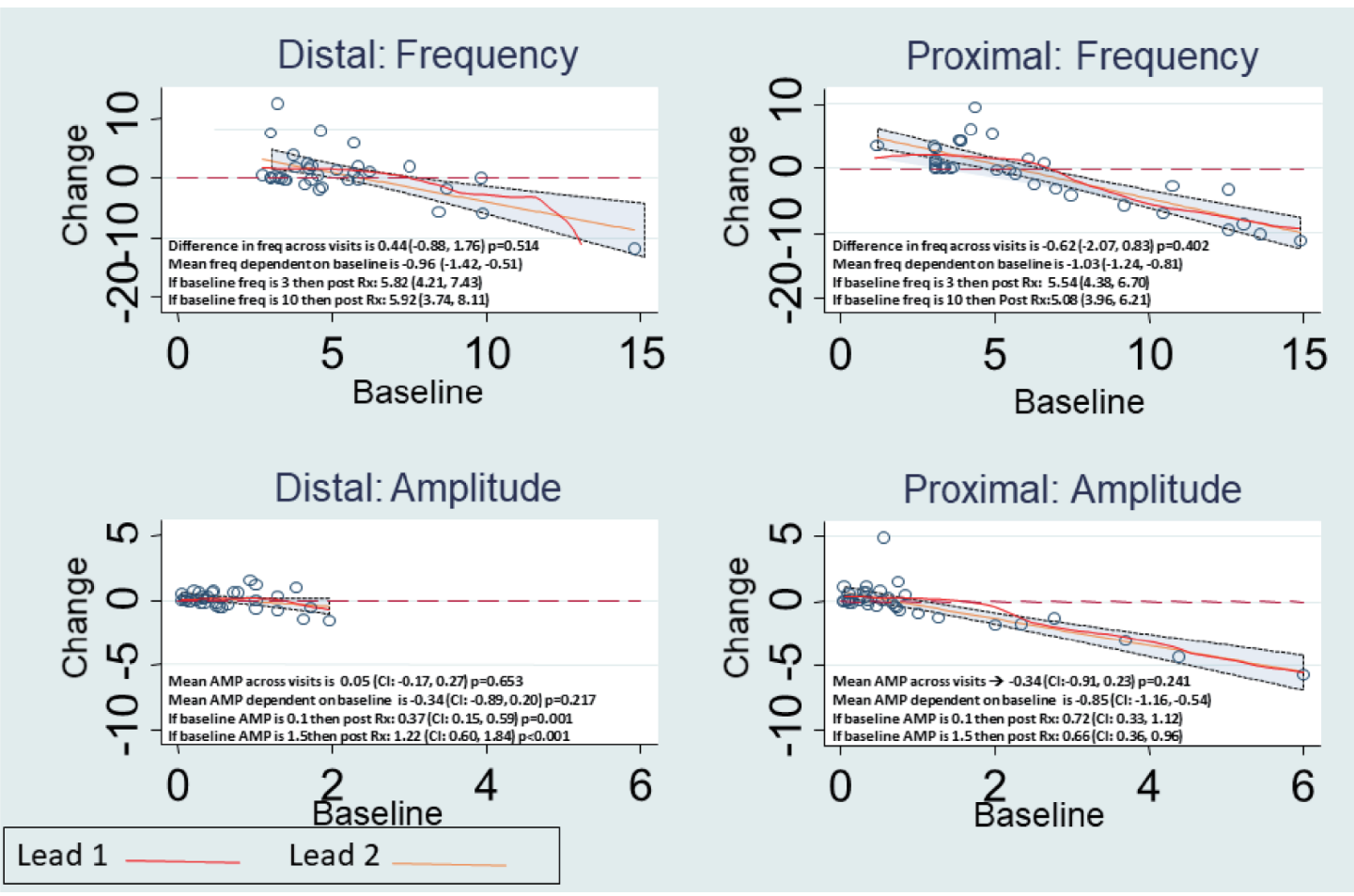

Figure 1. Observed change in Mucosal Frequency and Amplitude for Proximal and Distal Leads, with details as noted in each panel.

the presence of arrhythmias on EGG [22]. The role of gastric arrhythmias and developing of gastroparesis symptoms, especially nausea, remains controversial [26]. Prior studies showed that there is a persistent connection between arrhythmias and nausea development in motion sickness simulations, including electrical rhythm disturbances with their severity correlating with nausea intensity [26-28]. Gastric arrhythmias can be differentiated into disorders of initiation, whereas slow wave initiation result from abnormalities to fundamental ICC frequencies, or disorders of conduction that result from a disruption to slow wave entrainment through ICC networks $[20,26]$.

The advent of gastric electrical stimulation has provided a treatment option for drug-refractory gastroparesis symptom patients. Recent novel advancements in micro implantable neurostimulators now allow for even less-invasive tGES implantation than the modified cardiac leads used [23]. Measurements of gastric electric activity using the cutaneous EGG have been reported as a positive predictive value of $65-100 \%$ for normal gastric emptying vs. $50-80 \%$ for predicting abnormal gastric emptying. While the exact relationship to gastric

Table 5. Changes, in Mean Symptom Score, as Well as Total Gastric Emptying Measured at Baseline and Post-Stimulation via 2-Lead tGES

\begin{tabular}{llll}
\hline Variable & Visit $\mathbf{1}$ & Visit $\mathbf{2}$ & Change $(\mathbf{C I})(\mathbf{P}$ value) \\
\hline Nausea & 3.46 & 1.73 & $-1.73(-2.5,-0.91)(<0.001)^{*}$ \\
Vomiting & 2.69 & 1.46 & $-1.23(-2.1,-0.4)(0.003)^{*}$ \\
\hline Anorexia & 3.04 & 2.08 & $-0.96(-1.9,-0.01)(0.047)^{*}$ \\
Bloating & 3.21 & 1.69 & $-1.52(-2.6,-0.4)(0.006)^{*}$ \\
\hline Abdominal pain & 2.75 & 1.38 & $-1.36(-2.7,-0.1)(0.038)$ \\
TSS & 15.38 & 8.27 & $-7.11(-11.1,-3.1)(<0.001)^{*}$ \\
Frequency & 6.45 & 5.96 & $-0.49(-2.9,1.9)(0.685)$ \\
Amplitude & 0.69 & 0.99 & $0.30(-0.3,0.9)(0.362)$ \\
Ratio & 26.43 & 11.49 & $-14.93(-26.9,-3.0)(0.014)^{*}$ \\
GET total & 109.04 & 120.55 & $11.51(-20.1,43.2)(0.48)$ \\
\hline
\end{tabular}

Frequency reported as cpm and amplitude reported as mV. TSS: total symptom score; GET Total: total gastric emptying time. All "Visit 2" values were recorded 5 days after baseline at visit 1 . ${ }^{*}$ The significant $P$ values. 
activity is unknown, the idea of using implanted leads to measure the gastric response to tGES through both single point and multiple sites, have been derived from similar electrical measurements at the time of surgery $[12,17,29]$ and low-resolution mapping can be achieved serosally at the time of GES insertion $[12,26,30]$.

We sought more knowledge on changes observed using tGES, which may further support the use of tGES as a predictive model for future response to pGES. We hypothesized that change in gastrointestinal symptoms, especially the VS as well as in gastric emptying may be observed via one implantable lead tGES. We further hypothesized that there would be a change observed in mean frequency, amplitude, and FAR with tGES via one lead versus two implantable leads [26, 31]. The significant reduction of nausea and vomiting symptoms diminished patient dependence on antiemetics as well exposure to side effects. One major limitation of antiemetic compliance, especially of anti-emetics targeting D2 receptors like metoclopramide, is neuropsychic imbalances causing drug-induced Parkinson, tardive dyskinesia, as well as metabolic imbalances [32]. While some gastroparesis patient symptoms may be managed by anti-emetics, a significant number will develop some degree of resistance requiring a GES to manage symptoms.

In this study, both gastric electrical frequency and amplitude changed in response to electrical stimulation, although the changes were not always significant; and other studies have noted stimulation to increase fundic accommodation [11, 19, $27,31,33]$. These gastric fundic changes may be the result of decreased frequency and amplitude observed in the proximal gastric mucosa after tGES, as low mucosal frequencies at EGG increased, and higher ones decreased, toward a mean value of $5.027 \mathrm{cpm}$. Other studies have noted stimulation may increase fundic accommodation [27, 34]. The direction of change was similar to that observed in a separate study on pGES, which noted a decrease in frequency from $5.06 \mathrm{cpm}$ pre-GES to 3.66 post-GES [7]. In the current study, both PROX frequency and amplitude decreased with tGES stimulation, although the changes were not significant. Thus, the possible proximal gastric effects may correlate to the decreased frequency and amplitude observed in proximal gastric mucosal recordings.

In this current study, mEG frequency values were compared to patient-reported vomiting scores and patients who vomited less prior to tGES also had lower baseline mucosal EG frequencies. A previous study in healthy subjects found good to moderate reproducibility of cutaneous EGG frequency on consecutive days, as well as at least 2 weeks later [29]. Two studies using tGES have supported decreases in vomiting score with stimulation [22]. Another study has shown a reduction in vomiting score within $72 \mathrm{~h}$ of tGES [33]. In a doubleblind, randomized, controlled, crossover study involving 33 gastroparesis patients, implantable GES resulted in 14\% lower self-reported vomiting frequencies when the device was "on" compared with times when the device was deactivated [35].

In a published study including 214 patients with over 10year follow-up, there were improvements in vomiting (62\% improved), nausea (59\% improved) and total gastrointestinal symptoms ( $84 \%$ improved), after permanent GES implantation [36]. In another long-term follow-up study of GES in intractable nausea and vomiting, 15 of 27 patients (56\%) reported improved quality-of-life score at 5 years post-device implantation $[22,37]$. The reduced nausea and vomiting symptoms significantly reduce patient's dependence on anti-emetic medications as well as possible medication side effects. Patients with higher baseline frequencies at EGG responded better to tGES. Alternative modes of stimulation, such as electroacupuncture, have also noted restoration of gastric accommodation in a study on five vagotomized dogs [34] as well as a separate study on diabetic rats [25]. This modality of stimulation is believed to improve gastric slow waves by its excitatory effect on vagal tone [38]. The higher average amplitude at baseline measured through the proximal lead may suggest a higher degree of dysrhythmia in the body of the stomach (the site of proximal lead implantation) as compared to the distal lead implantation.

A noted change of increased frequency at the distal lead, though not significant in our analysis, has been supported from prior studies. Analysis using multichannel electrical measures $[3,10,39]$, as well as a multiscale model simulating slow wave propagation, noted the higher power of dominant frequency $(3.0 \mathrm{cpm})$ in the distal EGG electrode than in the proximal channels [10, 39-41]. Biopsy specimens and high-resolution mapping may provide a patho-electrophysiological explanation for higher amplitudes [26, 28]. Our findings were perhaps limited by restricted recording time of mucosal electrophysiology and variation in electrode placement. Future improvements of similar studies would include more precise recording devices, larger study size and greater standardization of electrode placement.

\section{Conclusions}

Low-resolution mapping via placement of low-resolution two mucosal leads by temporary endoscopic GES appears to be a beneficial method of understanding the pathophysiology of gastroparesis. New methods of analyzing gastric wave propagation patterns in spatiotemporal using high-resolution detail may provide further meaning for electrophysiologic changes noted by stimulation. Future studies should assess the relationship between symptom relief and specific electrophysiologic changes in the gastric mucosa in response to GES, as well as possible benefits of titration of stimulator parameters to tailor to individual patients.

\section{Acknowledgments}

The authors would like to thank the staff of the University of Mississippi Medical Center for help in obtaining these studies. They would also like to thank Drs. Chris Lahr and Brittain Heindl and Danielle Spree FNP for their help in this work, as well as Catherine McBride at the University of Louisville for help in manuscript preparation.

\section{Disclosures}

Dr. Abell is a former licensee, consultant, and investigator for 
Medtronic, Inc. Dr. Abell received grant support from Theravance, Allergan and Vanda, and is a consultant for Theravance; an editor for MedStudy, Neuromodulation and Wikistim; a reviewer for UpToDate; and the founder of ADEPT-GI. The other authors disclosed no financial relationships relevant to this publication. The University of Mississippi has been awarded an Intellectual Property claim regarding some aspects of the technology used in this study that has been assigned to ADEPT-GI.

\section{References}

1. Parkman HP, Yates K, Hasler WL, Nguyen L, Pasricha PJ, Snape WJ, Farrugia G, et al. Clinical features of idiopathic gastroparesis vary with sex, body mass, symptom onset, delay in gastric emptying, and gastroparesis severity. Gastroenterology. 2011;140(1):101-115.

2. Atassi H, Abell TL. Gastric Electrical Stimulator for Treatment of Gastroparesis. Gastrointest Endosc Clin N Am. 2019;29(1):71-83.

3. Parkman HP, Hasler WL, Barnett JL, Eaker EY, American Motility Society Clinical GI Motility Testing Task Force. Electrogastrography: a document prepared by the gastric section of the American Motility Society Clinical GI Motility Testing Task Force. Neurogastroenterol Motil. 2003;15(2):89-102.

4. Chen JD, McCallum RW. Clinical applications of electrogastrography. Am J Gastroenterol. 1993;88(9):13241336.

5. Yin J, Levanon D, Chen JD. Inhibitory effects of stress on postprandial gastric myoelectrical activity and vagal tone in healthy subjects. Neurogastroenterol Motil. 2004;16(6):737-744.

6. Coleski R, Hasler WL. Directed endoscopic mucosal mapping of normal and dysrhythmic gastric slow waves in healthy humans. Neurogastroenterol Motil. 2004;16(5):557-565.

7. Williams PA, Nikitina Y, Kedar A, Lahr CJ, Helling TS, Abell TL. Long-term effects of gastric stimulation on gastric electrical physiology. J Gastrointest Surg. 2013;17(1):50-55; discussion p 55-56.

8. O'Grady G, Angeli TR, Du P, Lahr C, Lammers W, Windsor JA, Abell TL, et al. Abnormal initiation and conduction of slow-wave activity in gastroparesis, defined by high-resolution electrical mapping. Gastroenterology. 2012;143(3):589-598 e583.

9. Chen JD, Schirmer BD, McCallum RW. Serosal and cutaneous recordings of gastric myoelectrical activity in patients with gastroparesis. Am J Physiol. 1994;266(1 Pt 1):G90-98.

10. Mirizzi N, Scafoglieri U. Optimal direction of the electrogastrographic signal in man. Med Biol Eng Comput. 1983;21(4):385-389.

11. Egbuji JU, O'Grady G, Du P, Cheng LK, Lammers WJ, Windsor JA, Pullan AJ. Origin, propagation and regional characteristics of porcine gastric slow wave activity determined by high-resolution mapping. Neurogastroenterol Motil. 2010;22(10):e292-300.
12. Qian LW, Pasricha PJ, Chen JD. Origins and patterns of spontaneous and drug-induced canine gastric myoelectrical dysrhythmia. Dig Dis Sci. 2003;48(3):508-515.

13. Mintchev MP, Kingma YJ, Bowes KL. Accuracy of cutaneous recordings of gastric electrical activity. Gastroenterology. 1993;104(5):1273-1280.

14. Hamilton JW, Bellahsene BE, Reichelderfer M, Webster JG, Bass P. Human electrogastrograms. Comparison of surface and mucosal recordings. Dig Dis Sci. 1986;31(1):33-39.

15. Abell TL, Malagelada JR. Glucagon-evoked gastric dysrhythmias in humans shown by an improved electrogastrographic technique. Gastroenterology. 1985;88(6):19321940.

16. . Federal Registry. 2000;65:78945-78946.

17. Lin Z, Forster J, Sarosiek I, McCallum RW. Treatment of gastroparesis with electrical stimulation. Dig Dis Sci. 2003;48(5):837-848.

18. Eagon JC, Kelly KA. Effect of electrical stimulation on gastric electrical activity, motility and emptying. Neurogastroenterol Motil. 1995;7(1):39-45.

19. Tougas G, Huizinga JD. Gastric pacing as a treatment for intractable gastroparesis: shocking news? Gastroenterology. 1998;114(3):598-601.

20. Abell TL, Van Cutsem E, Abrahamsson H, Huizinga JD, Konturek JW, Galmiche JP, VoelIer G, et al. Gastric electrical stimulation in intractable symptomatic gastroparesis. Digestion. 2002;66(4):204-212.

21. Ayinala S, Batista O, Goyal A, Al-Juburi A, Abidi N, Familoni B, Abell T. Temporary gastric electrical stimulation with orally or PEG-placed electrodes in patients with drug refractory gastroparesis. Gastrointest Endosc. 2005;61(3):455-461.

22. Abell TL, Johnson WD, Kedar A, Runnels JM, Thompson J, Weeks ES, Minocha A, et al. A double-masked, randomized, placebo-controlled trial of temporary endoscopic mucosal gastric electrical stimulation for gastroparesis. Gastrointest Endosc. 2011;74(3):496-503 e493.

23. Deb S, Tang SJ, Abell TL, Rao S, Huang WD, To SD, Lahr C, et al. An endoscopic wireless gastrostimulator (with video). Gastrointest Endosc. 2012;75(2):411-415, e411.

24. Daram SR, Tang SJ, Abell TL. Video: temporary gastric electrical stimulation for gastroparesis: endoscopic placement of electrodes (ENDOstim). Surg Endosc. 2011;25(10):3444-3445.

25. Yin J, Chen J, Chen JD. Ameliorating effects and mechanisms of electroacupuncture on gastric dysrhythmia, delayed emptying, and impaired accommodation in diabetic rats. Am J Physiol Gastrointest Liver Physiol. 2010;298(4):G563-570.

26. O'Grady G, Egbuji JU, Du P, Lammers WJ, Cheng LK, Windsor JA, Pullan AJ. High-resolution spatial analysis of slow wave initiation and conduction in porcine gastric dysrhythmia. Neurogastroenterol Motil. 2011;23(9):e345355.

27. Kindt S, Tack J. Impaired gastric accommodation and its role in dyspepsia. Gut. 2006;55(12):1685-1691.

28. O'Grady G, Wang TH, Du P, Angeli T, Lammers WJ, 
Cheng LK. Recent progress in gastric arrhythmia: pathophysiology, clinical significance and future horizons. Clin Exp Pharmacol Physiol. 2014;41(10):854-862.

29. Jonderko K, Kasicka-Jonderko A, Krusiec-Swidergol B, Dzielicki M, Stroj L, Dolinski M, Dolinski K, et al. How reproducible is cutaneous electrogastrography? An indepth evidence-based study. Neurogastroenterol Motil. 2005;17(6):800-809.

30. Angeli TR, Cheng LK, Du P, Wang TH, Bernard CE, Vannucchi MG, Faussone-Pellegrini MS, et al. Loss of interstitial cells of cajal and patterns of gastric dysrhythmia in patients with chronic unexplained nausea and vomiting. Gastroenterology. 2015;149(1):56-66 e55.

31. Weeks ES, Amin O, Griswold M, Sunesara I, Kedar A, Abell TL. Mucosal temporary gastric stimulation for patients with symptoms of gastroparesis: proximal vs. distal leads stimulation. Gastroenterology. 2011;140(5):S-378.

32. Herrstedt J. Risk-benefit of antiemetics in prevention and treatment of chemotherapy-induced nausea and vomiting. Expert Opin Drug Saf. 2004;3(3):231-248.

33. Abell TL, Familoni B, Voeller G, Werkman R, Dean P, Waters B, Smalley D, et al. Electrophysiologic, morphologic, and serologic features of chronic unexplained nausea and vomiting: lessons learned from 121 consecutive patients. Surgery. 2009;145(5):476-485.

34. Ouyang H, Xing J, Chen J. Electroacupuncture restores impaired gastric accommodation in vagotomized dogs.
Dig Dis Sci. 2004;49(9):1418-1424.

35. Abell T, McCallum R, Hocking M, Koch K, Abrahamsson H, Leblanc I, Lindberg G, et al. Gastric electrical stimulation for medically refractory gastroparesis. Gastroenterology. 2003;125(2):421-428.

36. Anand C, Al-Juburi A, Familoni B, Rashed H, Cutts T, Abidi N, Johnson WD, et al. Gastric electrical stimulation is safe and effective: a long-term study in patients with drug-refractory gastroparesis in three regional centers. Digestion. 2007;75(2-3):83-89.

37. Gourcerol G, Huet E, Vandaele N, Chaput U, Leblanc I, Bridoux V, Michot F, et al. Long term efficacy of gastric electrical stimulation in intractable nausea and vomiting. Dig Liver Dis. 2012;44(7):563-568.

38. Yin J, Chen JD. Gastrointestinal motility disorders and acupuncture. Auton Neurosci. 2010;157(1-2):31-37.

39. Chen J, Vandewalle J, Sansen W, van Cutsem E, Vantrappen $\mathrm{G}$, Janssens J. Observation of the propagation direction of human electrogastric activity from cutaneous recordings. Med Biol Eng Comput. 1989;27(5):538-542.

40. Du P, O'Grady G, Cheng LK, Pullan AJ. A multiscale model of the electrophysiological basis of the human electrogastrogram. Biophys J. 2010;99(9):2784-2792.

41. Lin Z, Chen JD, Schirmer BD, McCallum RW. Postprandial response of gastric slow waves: correlation of serosal recordings with the electrogastrogram. Dig Dis Sci. 2000;45(4):645-651. 